\title{
Septoplasty with concomitant inferior turbinate reduction reduces the need for revision procedure*
}

\author{
Therese R. Karlsson', Muhammad Shakeel², Mrinal Supriya², Bhaskar Ram², Rhinology 53:59-65, 2015 \\ Kim W. Ah-See ${ }^{2}$ \\ DOl:10.4193/Rhino12.059 \\ I Sahlgrenska University Hospital, Gothenburg, Sweden \\ *Received for publication: \\ April 4, 2012 \\ 2 Department of Otolaryngology - Head and Neck Surgery, University of Aberdeen, Aberdeen Royal Infirmary \\ Accepted: August 23, 2014
}

\section{Abstract \\ Objective}

Septoplasty is an accepted and common surgical intervention to improve the nasal airway. However, the role of concomitant surgery on the inferior turbinate remains debated. This study aims to investigate if the inferior turbinate surgery at the time of septoplasty would impact on the likelihood of revision nasal surgery - septoplasty or septorhinoplasty.

\section{Study design}

Retrospective review of consecutive patients undergoing septoplasty with or without inferior turbinate reduction over 12 years (1998 - 2010) at Aberdeen Royal Infirmary.

\section{Methods}

Patients were identified from the theatre log books and were excluded if they underwent any other nasal procedure. Data collected include demographics, type of primary surgery, and grade of surgeon along with revision nasal surgery in this cohort.

\section{Results}

2168 eligible patients with a mean age of 39 years were investigated. Two groups were identified: Group A, with 788 patients who underwent septoplasty only, and Group B, in which 1380 patients underwent septoplasty with concomitant inferior turbinate reduction. The majority of operations were performed by the surgeons in training. The incidence of revision surgery was $5.1 \%$ (21 revision septoplasties and 19 corrective septorhinoplasties) in Group A compared to $2.2 \%$ (20 revision septoplasties and 10 corrective septorhinoplasties) in Group B.

\section{Conclusion}

Based on this study, it would appear that concomitant inferior turbinate reduction may decrease the likelihood of revision nasal surgery.

Key words: septoplasty, revision surgery, inferior turbinate. level of evidence: 4

\section{Introduction}

Septal deviation has been recorded in all ages and all races with varying degrees of prevalence ${ }^{(1)}$. Up to $75 \%$ of the population has some degree of nasal deformity, most commonly septal deviation ${ }^{(2,3)}$. However, not everyone experience clinical manifestations of this anatomical abnormality ${ }^{(1)}$. The inferior turbinate (IT) appears more prone to hypertrophy than the middle or superior turbinates and may occur as a compensatory mechanism in patients with septal deviation, where the enlarged turbinate is found on the opposite side of the septal deviation ${ }^{(4)}$. This is explained physiologically as the abnormal septum increases the nasal cavity space on the contralateral side. Consequently, more air will flow through the area and so, the IT increases in size to maintain the ratio of air flow to mucosal surface area to effectively humidify the increased quantities of air ${ }^{(2,5)}$. However, this expansion in size may lead to significant 
mechanical obstruction as the turbinate itself forms part of the internal nasal valve, which is the narrowest point of airflow through the nose ${ }^{(6)}$.

Although it is well-established in current literature that the IT does enlarge, there is much debate regarding what parts of the turbinate hypertrophy; conchal bone or erectile mucosa. Egeli et al. ${ }^{(4)}$ argued that the increased volume was accounted for by the two-fold enlargement of conchal bone they demonstrated in 32 patients. It was measured using computed tomography and deemed significant with a $p$-value of less than 0.05 . The authors also concluded that the mucosal enlargement only played a minor role, which was supported by Berger et al. ${ }^{(7)}$. On the contrary, in cases of turbinate hypertrophy where rhinitis is the underlying pathology, the enlargement is mainly caused by an increase in volume of erectile mucosa ${ }^{(8)}$. A third accepted theory argues that significant increases in both bone and mucosa take place ${ }^{22,5,9)}$. Hence, varying evidence exists for the composition of the hypertrophied turbinate, possibly due to failure to correct identification of the underlying cause. If an inflammatory reaction is responsible, such as in rhinitis, mucosal hypertrophy is more likely, whereas if due to a septal deviation compensatory response, the bony component may be more significant. There is an overwhelming amount of evidence supporting septoplasty as an effective and definitive treatment option for the deviated nasal septum. Many measures for determining its efficacy have been proposed and include both objective and subjective tools ${ }^{(10)}$. It is the third most commonly performed surgical procedure by otolaryngologists ${ }^{(10,11)}$. Septoplasty is taught in the United Kingdom to specialist registrars in their first year of training ${ }^{(12)}$. As the IT is often enlarged in patients with a deviated septum, turbinate manipulation may be performed in combination with septoplasty ${ }^{(13)}$. As turbinate enlargement is partly attributed to additional bony deposits in conjunction with mucosal hypertrophy, a change that is not naturally reversible, it is logical to perform turbinate surgery along with septoplasty ${ }^{(4)}$. Little literature exists to definitively establish the most effective technique for IT manipulation and subsequently, many techniques have been developed (2). The more popular techniques may be subdivided into two categories. The first reduces the IT by resecting bone and tissue and include trimming or turbinectomy ${ }^{(14)}$. The second category reduces the size by destructive measures resulting in shrinkage of the turbinate and includes diathermy, submucosal diathermy (SMD) and surface linear cautery ${ }^{(8,15)}$.

Although septoplasty produces satisfactory results in the majority of patients, some studies still report a significant proportion of patients being dissatisfied with their operation. This may be explained by poor procedural execution or due to inappropriate choice of surgical procedure. Depending on the underlying pathology, septoplasty in itself may not be sufficient to alleviate symptoms. If compensatory hypertrophy of the IT is present, septoplasty will only correct the obstruction on the deviated side, yet worsen symptoms on the contralateral side post-operatively. Consequently, the suggestion that IT reduction should be performed in conjunction with septoplasty has been proposed $^{(16)}$.

In light of the controversies in currently available literature regarding effectiveness of septoplasty with concomitant IT reduction versus septoplasty alone, this study aims to evaluate the practice at Aberdeen Royal Infirmary (ARI) over the past 12 years with the primary outcome measured being the need for revision nasal surgery following the primary septoplasty operation with or without IT reduction.

\section{Materials and Methods}

\section{Study design}

This study is a retrospective non-randomised observational study performed in a tertiary care facility, involving 2,168 consecutive patients presenting to the ENT Department at ARI for septoplasty during the 12-year period of 1998 to 2010 . Ethical approval for the compilation of the database was sought from and granted by the Department of Clinical Effectiveness.

\section{Selection criteria}

All patients undergoing a septoplasty operation with or without an additional IT procedure between March 1998 and December 2010 were included in the study. Any patient who simultaneously underwent other operations such as endoscopic sinus surgery, polypectomy or rhinoplasty were excluded. Patients who had a revision septoplasty within the time span but not a primary operation within the same 12 years were also excluded as no data regarding type of primary intervention was available.

\section{Surgical procedure}

Septoplasty was defined as a surgical procedure on the nasal septum to correct any existing deviations, which included open operations, endoscopic or extracoporal. Turbinate manipulation encompassed any procedure performed to reduce the size of inferior turbinates and included techniques such as SMD, complete and partial turbinectomy, and cautery. There were no set criteria for who should undergo septoplasty alone or receive concomitant turbinate manipulation. This was a multifactorial decision, which took in to account the underlying cause of septal deviation, patient symptomatology and the surgeon's clinical judgment.

\section{Data collection}

Patients were identified from theatre log books in the relevant ENT-theatres. Additional information was then collected from electronic hospital databases and outpatient clinic correspon- 


\section{Total Number of Primary} Operations

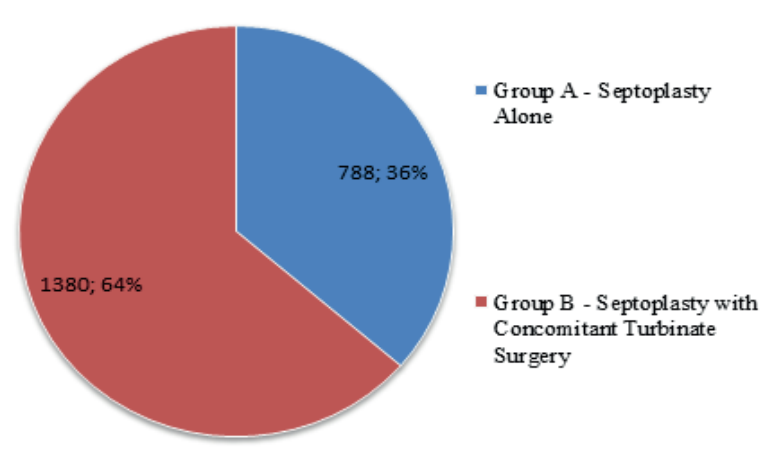

\section{Revision Operation Rates}

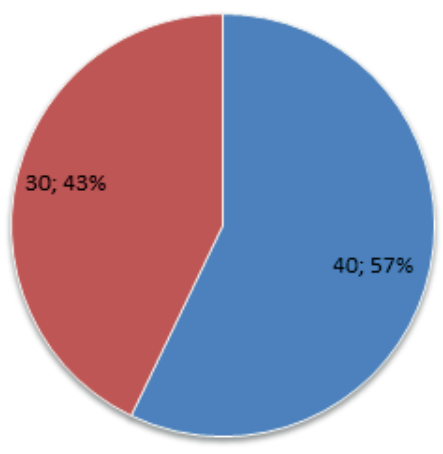

- Group A - Septoplasty

Alone

- Group B - S eptoplasty

with Concomitant

Turbinate Surgery

Figure 1. A) The total number of primary operations. B) The respective revision rates represented as a pie chart, clearly demonstrating that Group A has a higher revision rate in proportion to the number of primary operations compared to Group B.

dence, which included demographics, and date of primary and revision procedure. The presenting symptoms for a smaller sample cohort of 101 patients were analysed.

\section{Statistical analysis}

Microsoft Excel and SPSS were used for data collection and statistical analysis.

\section{Results}

A total of 2,303 operations were identified as either being primary septoplasty operations, with or without turbinate intervention, or revision procedures. After excluding patients with revision nasal surgery; including 70 valid revision nasal operations and 65 patients with revision operations but primary operation occurring outside the 12 year study period, a total of 2,168 patients were identified. Based on the primary operation the patients were divided into two groups $A$ and $B$.

Group A consisted of 788 patients who received septoplasty alone. The age range was $16-85$ with a mean of 39.5 years. 553 patients were male (70.2\%) and 235 were female (29.8\%). Group B consisted of 1,380 patients who, in addition to septoplasty also underwent bilateral inferior turbinate manipulation. The average age was 39.2 years with a range of $16-77$ years. The male to female ratio was in proportion to that of Group A, with 957 being male (69.4\%) and 423 being female (30.6\%).

As a primary outcome measure, this study looked at the need for revision nasal surgery as a measure of effectiveness of the primary operation. Of the 788 patients in Group A, 40 patients returned for additional corrective surgery (21 septoplasty and 19 septorhinoplasty procedures), resulting in an absolute revision rate of $5.08 \%$. In comparison, out of the 1,380 patients in Group $\mathrm{B}$, only 30 returned ( 20 for septoplasty and 10 for septorhino- plasty procedures), yielding a revision rate of $2.17 \%$. Consequently, Group B experienced an absolute reduction in the need for revision nasal surgery by $2.91 \%$ when compared to Group A. This was a statistically significant reduction $(p<0.001)$ and is represented diagrammatically in Figure $1 \mathrm{~A}$ and Figure 1B. Upon detailed analysis, we found that in group B, patients underwent reduction of inferior turbinate either by removal of anterior end of the IT or by submucosal diathermy of the IT. The incidence of revision nasal surgery was lowest $(2.1 \%)$ in the patients who underwent partial trimming of the IT at the time of septoplasty (Table 1).

For in depth analysis, a smaller cohort of 101 patients was selected at random attending for their primary operation between 2007 and 2010. Out of the 101 patients, 36 underwent septoplasty alone and of these two returned, resulting in a revision rate of $5.6 \%$, which is similar to that of the larger population sample. The remaining 66 had an additional turbinate reduction

Table 1. Incidence of revision surgery according to type of inferior turbinate intervention.

\begin{tabular}{|lccc|} 
& $\begin{array}{c}\text { Group 0: } \\
\text { Septoplasty } \\
\text { only }\end{array}$ & $\begin{array}{c}\text { Group 1: } \\
\text { Reduction } \\
\text { by Removal }\end{array}$ & $\begin{array}{c}\text { Group 2: } \\
\text { Reduction by } \\
\text { Electrocauterie }\end{array}$ \\
\hline $\begin{array}{l}\text { Total Patients } \\
788\end{array}$ & 852 & 409 \\
$\begin{array}{l}\text { Revision } \\
\text { Septoplasties }\end{array}$ & 19 & 12 & 8 \\
$\begin{array}{l}\text { Corrective } \\
\text { Septorhinoplasty }\end{array}$ & 21 & 6 & 3 \\
\hline $\begin{array}{l}\text { Total } \\
\text { Revision Rate (\%) }\end{array}$ & $40(5,1 \%)$ & $18(2,1 \%)$ & $11(2,7 \%)$ \\
\hline
\end{tabular}


Table 2. Presenting symptoms of sample cohort.

\begin{tabular}{|c|c|c|c|c|c|c|}
\hline & $\begin{array}{c}\text { All Patients } \\
\text { Group A/B }\end{array}$ & $\begin{array}{c}\text { All Patients } \\
(\%)\end{array}$ & $\begin{array}{c}\text { Septoplasty } \\
\text { Only } \\
\text { Group A }\end{array}$ & $\begin{array}{c}\text { Septoplasty } \\
\text { Only } \\
\text { Group A (\%) }\end{array}$ & $\begin{array}{l}\text { Concomitant } \\
\text { Turbinate } \\
\text { Manipulation } \\
\text { Group B }\end{array}$ & $\begin{array}{l}\text { Concomitant } \\
\text { Turbinate } \\
\text { Manipulation } \\
\text { Group B (\%) }\end{array}$ \\
\hline Nasal Blockage & 101 & $99 \%$ & 36 & $100 \%$ & 65 & $98.5 \%$ \\
\hline Snoring & 13 & $12.7 \%$ & 4 & $11.1 \%$ & 9 & $13.6 \%$ \\
\hline Nasal Discharge & 12 & $11,8 \%$ & 5 & $13.9 \%$ & 7 & $10.6 \%$ \\
\hline Itching and Sneezing & 11 & $10.8 \%$ & 2 & $13.6 \%$ & 9 & $13.6 \%$ \\
\hline Post Nasal Discharge & 9 & $8.8 \%$ & 3 & $8.3 \%$ & 6 & $9.1 \%$ \\
\hline Facial Pain & 9 & $8.8 \%$ & 2 & $5.6 \%$ & 7 & $10.6 \%$ \\
\hline Diagnosed Rhinitis & 6 & $5.9 \%$ & 1 & $2.8 \%$ & 5 & $7.6 \%$ \\
\hline Headache & 6 & $5.9 \%$ & 1 & $2.8 \%$ & 5 & $7.6 \%$ \\
\hline Sinusitis & 4 & $3.9 \%$ & 0 & $0 \%$ & 4 & $6.1 \%$ \\
\hline Epistaxis & 4 & $3.9 \%$ & 2 & $5.6 \%$ & 2 & $3.0 \%$ \\
\hline Hyposmia & 3 & $2.9 \%$ & 2 & $5.6 \%$ & 1 & $1.5 \%$ \\
\hline
\end{tabular}

and yielded a revision rate of $1.6 \%$, as only one patient returned for further corrective surgery. Their presenting symptoms were recorded from out-patient clinic correspondence and are listed in Table 2. Nearly all patients complained of nasal obstruction with the range of additional symptoms being equally distributed between the groups. There does not appear to be a higher rate of patients suffering from rhinitis, which would be indicated by symptoms such as nasal discharge, sneezing, itching and post-nasal discharge, allocated to undergo an additional IT reduction (Table 2 ).

\section{Discussion}

The benefits of performing septoplasty with concomitant IT reduction are a controversial issue. Currently, the indications for such surgery are unclear ${ }^{(9)}$. Some surgeons only perform the additional procedure if specific diseases, such as rhinitis, are present along with the septal deviation. Other surgeons include a turbinate procedure regardless of the presence of any IT hypertrophy or pathology, which may be based on the principle that a significant amount of patients with septal deviation also have some degree of turbinate hypertrophy on the side contralateral to the deviation ${ }^{(17,18)}$.

This study found an absolute reduction rate of $2.91 \%$ in the need for revision nasal surgery in patients undergoing septoplasty with concomitant IT reduction when compared to patients undergoing septoplasty alone, which was statistically significant $(p<0.001)$. This can be explained by the presence of IT enlargement in combination with a deviated septum in some patients. Hence, a combined procedure would yield higher efficacy rates compared to septoplasty alone as the latter only partially addresses the underlying pathology. However, even without IT hypertrophy present, reducing its size increases the nasal cavity space and further improves the patient's symptoms, thereby explaining the reduction in number of revision procedures. Moreover, symptomatic relief from septoplasty alone may be highly dependent on the surgeon's skills, whereas when IT reduction is added, the septal aspect of the surgery does not need to be done perfectly to relieve nasal obstruction due to the further space provided by the additional procedure.

The revision rates for septoplasty alone in published literature is widely accepted to range from $5 \%$ to $8 \%{ }^{(19,20)}$.Thus, ARI's revision rate of $5.3 \%$ is at the low end of that range. However, there is no corresponding figure available addressing the revision nasal surgery rates for septoplasty with concomitant turbinate manipulation as no studies presently use the need for revision surgery as an outcome measure for assessing effectiveness. Nonetheless, there are other comparative studies investigating the efficacy of septoplasty with or without turbinate intervention that support the findings of this study.

A study by Lindemann et al ${ }^{(21)}$. had a population sample of 12 patients undergoing septoplasty of which six patients also received turbinoplasty. Although both groups experienced an increase in end-inspiratory air temperature and absolute humidity, the latter group measured an additional increase in both temperature, of $0.5^{\circ} \mathrm{C}(8.3 \%)$, and humidity, of $2.5 \mathrm{~g} /$ $\mathrm{m}^{3}$ (13.1\%), compared to the septoplasty only group. Both cohorts had similar pre-operative measures, which strengthens the findings of the study, yet it is let down by the small study sample. Furthermore, Gandomi et al. ${ }^{(11)}$ also demonstrated that 66 patients undergoing additional turbinate manipulations experienced statistically significant earlier symptomatic relief than the control group. This was subjectively established by patient perception of nasal blockage at three and six months post-operatively, which in turn is subject to varying pain 
thresholds of individual patients. Jun et al. ${ }^{(9)}$ utilised computed tomography to establish that the turbinate hypertrophy present in patients with significant septal deviation is more likely to be osseous rather than mucosal, thereby emphasising that an additional turbinate reduction would be a valuable complement to septoplasty operations.

In contrast to Grymer et al. ${ }^{(18)}$ and Jun et al. ${ }^{(9)}$, Busaba and Hossain ${ }^{(17)}$ demonstrated that all 40 patients presenting with septal deviation, with or without hypertrophy of the IT, gained benefit from a combination procedure as the overall Nasal Health Survey scores improved significantly from 52.3 to 76.6 , indicating symptomatic improvement and reduction in medication use. Although this study supports these results, findings must be interpreted with caution as the patient sample only included elderly individuals, which is therefore not representative of the entire population. The increasing support for addition of turbinate manipulations to septoplasty is further strengthened by Leong et al., (22) who reviewed 11 studies totalling 730 patients. On the contrary, Arunachalam et al. ${ }^{(23)}$ and Siegel et al. ${ }^{(10)}$ both agree that patients receive no extra benefit from an additional turbinate. This contrasts the finding of our study and one plausible explanation is the use of different outcome measures. The major issue highlighted when comparing our results to the currently available published literature is the vast array of outcome measures. As demonstrated, authors employ both subjective and objective measures. A universal outcome measure is needed to facilitate accurate inter-study comparison.

An additional factor that may increase the need for revision surgery includes prevalence of specific presenting symptoms. If applicable, certain symptoms should be more prevalent in either Group A or Group B. However, this was not at all the case as the initial symptoms were proportionally distributed between the two groups. These results are contradicted by other studies, which argue that patients with increasingly severe symptoms benefit more from a combined procedure as opposed to septoplasty alone ${ }^{(9,18)}$. The discrepancy between the above findings and those established in this study may be explained as the outcomes measures differ and thusly, the success rate is defined differently.

The strength of this study undoubtedly lies in its number of patients and definitive outcome measure. To our knowledge, no other study in currently available published literature has a population sample of over 2,000. Additionally, an objective outcome measure of the defined need for revision surgery is not only unique but will also facilitate comparisons between future studies. Although it is an objective measure, it accounts for the patient's symptoms and combines these with the clinical opinion of an experienced surgeon and thusly, eliminates the argument that an objective outcome measure does not correspond to the patient's symptomatology.

The study is limited by its retrospective design, which does not allow for patient follow-up at specific points in time or access to perceptions of symptoms post-operatively nor did it allow the degree of septal deviation for each patient to be established pre-operatively. Consequently, severity of pre-operative symptoms could not be reliably established. The current literature recommends surgery on the inferior turbinates for refractory rhinitis but the type of surgical intervention remains debated. Even if the nasal septum is not deviated the inferior turbinates reduction is carried out in patients with severely hypertrophied inferior turbinates. If rhinitis co-exist with septal deviation it is imperative that both conditions are dealt with in the same sitting. A limited literature review reveals a number of studies supporting the current practice and efficacy of inferior turbinate reduction ${ }^{(24-27)}$. In our cohort it was not possible to establish the exact incidence of rhinitis in the whole cohort but all of our patients had a septal deviation as the primary indication of surgery. Due to the large number of patients, only a sample cohort of 101 patients were reviewed regarding clinical indication for the primary operation in terms of nasal blockage and presence of additional presenting symptoms. A symptoms analysis in randomly selected patients revealed near normal distribution of symptoms in our two study groups. However, by combining the documented rhinitis and sinusitis it would appear that these conditions were more prevalent in patients undergoing inferior turbinate reduction at the time of septoplasty.

The study could not establish which patients suffered from IT hypertrophy and if so, to what degree this enlargement was osseous or mucosal, which may have influenced the efficacy of a combined procedure or increased the failure rate for septoplasty alone. The study does not, again due to its retrospective nature, address the issue of differences in post-operative complication rates for the septoplasty alone and the concomitant turbinate intervention. Although one study demonstrated no difference in minor complications, adverse events such as septal perforations and synechia were more frequent in those undergoing concomitant turbinate surgery ${ }^{(18)}$. Feldman et al. ${ }^{(28)}$ also reported an increased readmission rate for patients undergoing combined surgery. These findings are not surprising as performing an additional turbinate procedure is a more invasive and extensive procedure. It is not possible to ascertain that patients in the 2 groups did not have revision surgery elsewhere. However, our catchment area is a very unique geographical area of Scotland. Rarely patients move out of this region permanently, our patients tend to return to us if further surgery is required. However, we accept that it would have been ideal to confirm this aspect by contacting the patients at the time of the study which was beyond the scope of the current study.

Areas within septoplasty and IT manipulation that require further research have clearly been highlighted. For instance, should a turbinate procedure be added to septoplasty in all pa- 
tients or just for those whose symptoms are particularly severe or have a specified degree of IT hypertrophy? As mentioned, the complication rates between the two procedures also need to be investigated. Finally, the lasting benefits of septoplasty need to be addressed and any potential additional benefit of also performing concomitant turbinate surgery investigated.

\section{Conclusion}

This study found that septoplasty with concomitant IT reduction would appear to decrease the likelihood of revision nasal procedures when compared to patients undergoing septoplasty alone. Nevertheless, the authors cannot at this stage advocate that all septoplasty procedures should be accompanied by a turbinate intervention before the number needed to harm has been clearly established, which thusly will allow the calculation of a risk to benefit ratio upon which further recommendations can be made.

\section{Acknowlegdement}

Poster presentation: the annual meeting of the Association of Surgeons in Training (ASiT), 15-17 April 2011, Sheffield, England, United Kingdom.

\section{Authorship contribution}

TRK: data collection and analysis, literature review, manuscript preparation and submission; MSh: study concept and design, data collection and analysis, literature review, manuscript preparation and submission; MSu: data analysis, literature review, manuscript preparation and finalisation; BR: data analysis, literature review, manuscript preparation and finalisation, consultant in charge; KWAS: study concept, data analysis, literature review, manuscript preparation and finalisation, overall supervisor.

\section{Conflicts of Interest}

None

\section{References}

1. Sooknundun M, Kacker SK, Bhatia R, Deka RC. Nasal septal deviation: effective intervention and long term follow-up. Int J Pediatr Otorhinolaryngol 1986; 12: 65-72.

2. Kim DH, Park HY, Kim HS, et al. Effect of Septoplasty on Inferior Turbinate Hypertrophy. Arch Otolaryngol Head Neck Surg 2008; 134: 419-423.

3. Huang H, Lee T, Huang C, Chang P, Huang S Non-sinusitis rhinogenous headache: a tenyear experience. Am J Otolaryngol 2008; 29: 326-332.

4. Egeli E, Demirci L, Yazycy B, Harputluoglu U. Evaluation of the Inferior Turbinate in Patients With a Deviated Nasal Septum by Using Computed Tomography. Laryngoscope 2004; 114: 113-117.

5. Akoglu E, Karazincir S, Balci A, Okuyucu S, Sumbas H, Dagli AS. Evaluation of the turbinate hypertrophy by computed tomography in patients with deviated nasal septum. Otolaryngol Head Neck Surg 2007; 136: 380-384

6. Guss J, Thaler ER. Rhinosinusitis. 1st Ed. Philadelphia: Springer Science; 2008.

7. Berger G, Hammel I, Berger R, Avraham S, Ophir D. Histopathology of the inferior turbinate with compensatory hypertrophy in patients with deviated septum. Laryngoscope 2010; 110: 2100-2105.

8. Fradis M, Malatskey S, Magamsa I, Golz A Effect of Submucosal Diathermy in Chronic Nasal Obstruction Due to Turbinate Enlargement. Am J Otoloryngol 2002; 23: 332-336.

9. Jun BC, Kim SW, Kim SW, Cho JH, Park YJ, Yoon HR. Is turbinate surgery necessary when performing a septoplasty? Eur Arch Otorhinolaryngol 2009; 266: 975-980.

10. Siegel NS, Gliklich RE, Taghizadeh F, Chang
Y. Outcomes of septoplasty. Otolaryngol Head Neck Surg 2000; 122: 228-232.

11. Gandomi B, Bayat A, Kazemei T. Outcomes of septoplasty in young adults: the Nasal Obstruction Septoplasty Effectiveness study. Am J Otolryngol 2010; 31: 189-192.

12. Marshall $A H$, Johnston MN, Jones NS Principles of septal correction. J Laryngol Otol 2004; 118: 129-134.

13. Bahman G, Uzzo C, Scull H. A Practical Classification of Septonasal Deviation and an Effective Guide to Septal Surgery. Plast Reconstr Surg 1999; 104: 2202-2209.

14. Stewart MG, Smith TL, Weaver AM, et al. Outcomes after nasal septoplasty: Results from the Nasal Obstruction Septoplasty Effectiveness (NOSE) Study. Otolaryngol Head Neck Surg 2004; 130: 283-290.

15. Jackson LE, Koch RJ. Controversies in the Management of Inferior Turbinate Hypertrophy: A Comprehensive Review. Plast Reconstr Surg 1999; 103: 300-312.

16. Dinis PB, Haider H. Septoplasty: Long-Term Evaluation of Results. Am J Otolaryngol 2002; 23: 85-90.

17. Busaba NY, Hossain M. Clinical Outcomes of Septoplasty and Inferior Turbinate Reduction in the Geriatric Veterans' Population. Am J Rhinol 2004; 18: 343-347.

18. Grymer LF, Illum P, Hilberg O. Septoplasty and compensatory inferior turbinate hypertrophy: a randomized study by evaluated acoustic rhinometry. J Laryngol Otol 1993; 107: 413-417

19. Gubisch, W. Twenty-Five Years Experience with Extracorporeal Septoplasty. Facial Plast Surg 2006; 22: 230-239.

20. Sedwick JD, Lopez AB, Gajewski BJ, Simons RL. Caudal Septoplasty for Treatment of Septal Deviation; Aesthetic and Functional Correction of Nasal Base. Arch Facial Plast
Surg 2005; 7: 158-162

21. Lindemann J, Keck T, Leiacker R, Dzida R, Wiesmiller K. Early influence of bilateral turbinoplasty combined with septoplasty on intranasal air conditioning. Am J Rhinol 2008; 22: 542-545.

22. Leong SC, Kubba H, White PS. A review of outcomes following inferior turbinate reduction surgery in children for chronic nasal obstruction. Int J Pediatr Otorhinolaryngol 2009; 74: 1-6.

23. Arunachalam PS, Kitcher E, Gray J, Wilson JA. Nasal septal surgery: evaluation of symptomatic and general health outcomes. Clin Otolaryngol Allied Sci 2001; 26: 367-370.

24. Gunhan K, Unlu H, Yuceturk AV, Songu M. Intranasal steroids or radiofrequency turbinoplasty in persistent allergic rhinitis: effects on quality of life and objective parameters. Eur Arch Otorhinolaryngol. 2011 Jun;268(6):845-50. doi: 10.1007/ s00405-010-1462-1. Epub 2010 Dec 28.

25. Jose J, Coatesworth AP. Inferior turbinate surgery for nasal obstruction in allergic rhinitis after failed medical treatment. Cochrane Database Syst Rev. 2010 Dec 8;(12):CD005235. doi: 10.1002/14651858. CD005235.pub2.

26. Parida PK, Santhosh K, Ganesan S, Surianarayanan G, Saxena SK. The efficacy of radiofrequency volumetric tissue reduction of hypertrophied inferior turbinate in allergic rhinitis.Indian J Med Sci. 2011 Jul;65(7):269-77. doi: 10.4103/00195359.107387

27. Chhabra N, Houser SM. Surgical options for the allergic rhinitis patient. Curr Opin Otolaryngol Head Neck Surg. 2012 Jun;20(3):199-204. doi: 10.1097/ MO0.0b013e328352b821.

28. Feldman EM, Koshy JC, Chike-Obi CJ, Hatef 
DA, Bullocks JM, Stal S. Contemporary techniques in inferior turbinate reduction: survey results of the American Society for Aesthetic Plastic Surgery. Aesthet Surg J 2010; 30: 672 -679.
Muhammad Shakeel, FRCSED

(ORL-HNS) Specialist Registrar

Department of Otolaryngology-Head

and Neck Surgery

University of Aberdeen

Aberdeen Royal Infirmary
Aberdeen AB25 2ZN

United Kingdom

Tel: +44-122-455 2100

Fax: +44-122-455 4569

E-mail: drshakeel@doctors.org.uk

\section{ADVERTISEMENT}

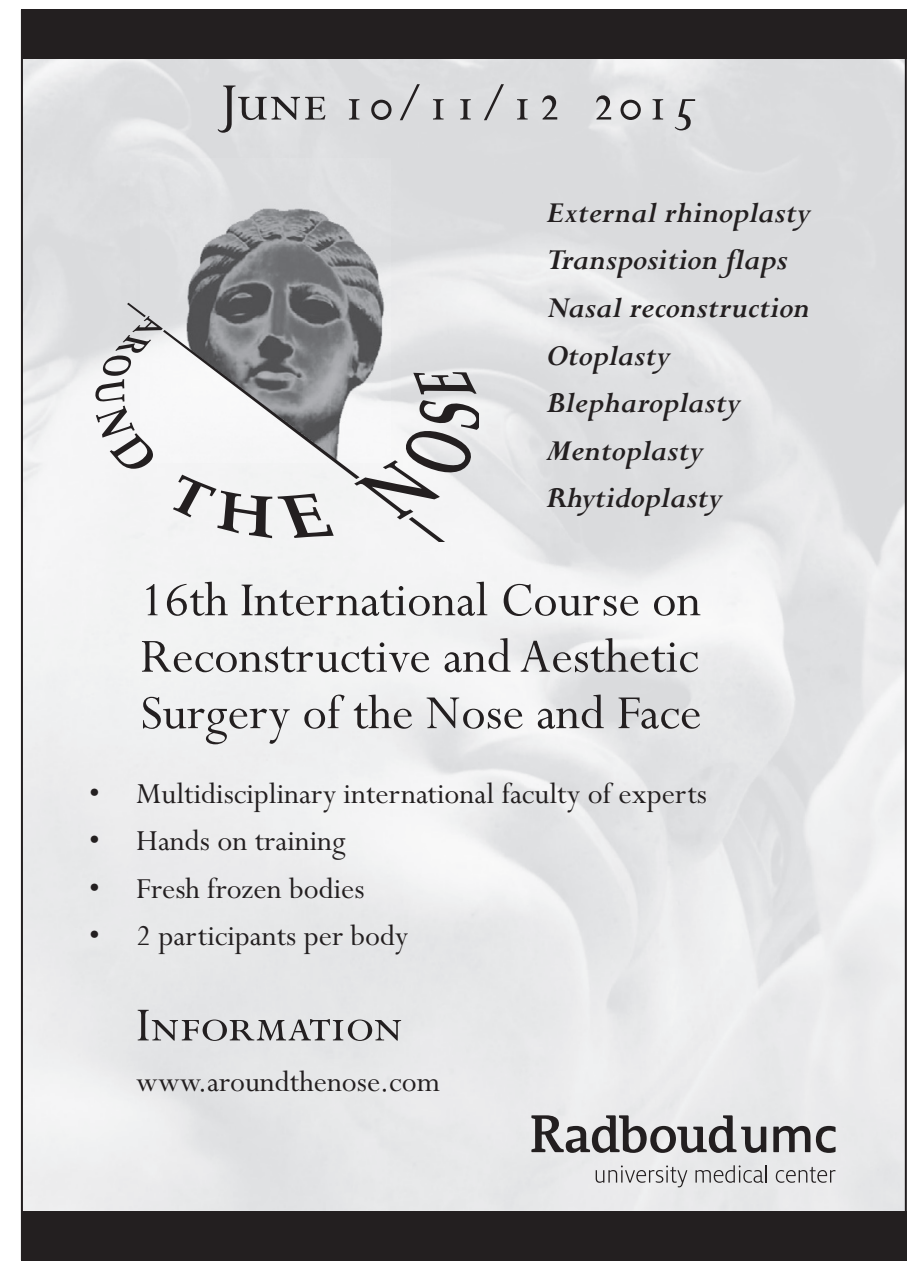

